\title{
REQUALIFICAÇÃO DE INFRAESTRUTURA URBANA: PROPOSTA PARA UMA NOVA PERIMETRAL
}

\author{
Bruno Borges Mamede ${ }^{1}$
}

\section{Lucas Devides Moreno²}

\section{Luís Soares Júnior ${ }^{3}$}

Resumo: Este artigo possui como objetivo demonstrar que estruturas urbanas tidas como obstáculos e causadoras de degradação da área de entorno podem ser requalificadas, não apenas para integrar o ambiente urbano, mas conferir novos usos dentro de sua destinação inicial. Também é possível aferir usos mais amplos e com maiores benefícios para a população local. O caso em questão neste estudo é uma nova proposta de uso para a chamada Avenida Perimetral, na cidade do Rio de Janeiro (RJ).

Palavras-chave: Geografia dos Transportes. Urbanismo sustentável. Transporte público integrado. Transit oriented development (TOD).

\section{INTRODUÇÃO: PROPOSTA E OBJETIVO}

Conforme mencionado, este artigo busca estudar a situação da Avenida Perimetral, localizada na zona portuária (desde os bairros de Cajú e São Cristóvão na Zona Norte até o Aeroporto Santos Dumont, no Centro da cidade, transpassando os bairros de Santo

\footnotetext{
${ }^{1}$ PEU/POLI/UFRJ / bruno.mamede@poli.ufrj.br

2 PEU/POLI/UFRJ / lucas.moreno@poli.ufr..br

${ }^{3}$ ADM/UGF / luis.junior@autoviacao1001.com.br
} 
Cristo, Saúde e Gamboa ao longo de seu percurso) em vista ao seu destino atual em face de um uso alternativo proposto pelos autores. Isto posto, este estudo apresenta a possibilidade de conversão em via ferroviária, completamente integrada aos principais eixos modais da cidade do Rio de Janeiro, em paralelo a criação de novos terminais e corredores de circulação para o transporte público, além da requalificação de toda a área de entorno do projeto.

O trecho em questão corresponde a 09 quilômetros de intervenção, sendo a maior parte, 7,5 quilômetros correspondentes a Avenida Perimetral propriamente dita e o restante uma extensão de seu percurso. Esta intervenção inicia-se na intersecção da Avenida Brasil com a Avenida João Goulart - Linha Vermelha segue paralela a primeira avenida até a subida da Avenida Perimetral, transpassando toda sua extensão elevada e o trecho final desde a sai descida até a Praça Senador Salgado Filho, em frente ao Aeroporto Santos Dumont e já situada no Central Bussiness District (CDB) da Região Metropolitana do Rio de Janeiro.

Acredita-se que a requalificação de estruturas e o seu aproveitamento racional para fins de implementos urbanísticos é capaz de promover em escala local (por exemplo) o desenvolvimento de áreas específicas de uma determinada cidade ou mesmo aglomerados urbanos. Corrobora-se desta maneira com as ideias de Rossi (2003) e Silva (2012) de que, mesmo sobre intervenção de grupos sociais distintos, a cidade pode desenvolver-se sobre critérios de racionalidade, otimização de usos e práticas sustentáveis.

Desta maneira, percebem-se não apenas benefícios econômico-financeiros, mas também outros mais complexos de mensuração numérica, contudo extremamente importantes para o cotidiano urbano. No objeto tratado neste artigo, uma avenida elevada na região central da segunda maior metrópole brasileira (IBGE, 2013), a sua nítida saturação nos horários de maior demanda proporciona grandes perdas de tempo aos usuários, bem como o aumento da poluição sonora e atmosférica do entorno, formação de ilhas de calor e desgaste dos componentes de cada automóvel em circulação.

\section{CONTEXTUALIZAÇÃO DA AVENIDA PERIMETRAL}

Esta via elevada foi construída durante os anos 1960 como opção de ligação expressa entre as zonas Norte e Sul da cidade do Rio de Janeiro (RJ). Esta conforta o trecho final de um conjunto de vias expressas que se inicia na orla de Copacabana até a entrada da Avenida Brasil, principal eixo de circulação entre as zonas Norte e Oeste, além do acesso a todas as estradas federais que chegam à cidade.

Atualmente, sua administração está englobada dentro do Projeto Porto Maravilha, primeira operação urbana consorciada do município. Esta é efetivada pela Prefeitura da Cidade do Rio de Janeiro (por intermédio da Companhia de Desenvolvimento da Região 
do Porto do Rio de Janeiro - CDURP) e o consórcio privado Porto Novo S/A. As leis complementares municipais (LCM/RJ) 101 e 102 de 2009 criaram e definiram os objetivos, agentes e termos da Operação Urbana Porto Maravilha, bem como a própria CDURP.

Dentre as principais metas da operação urbana está a demolição do trecho elevado da Avenida Perimetral entre o Terminal Rodoviário Novo Rio e o Aeroporto Santos Dumont. Como principais argumentos, a concessionária privada e o poder público defendem a integração entre o Porto do Rio de Janeiro (propriamente) dito e seus bairros lindeiros, reverter a degradação urbana causada pela estrutura da via e, principalmente, a saturação máxima atingida pela via.

Projetada para atender a 02 mil veículos por hora e por sentido em sua demanda máxima (horários de pico), o contingente atual alcança mais de 10 mil veículos. Suas quatro faixas (duas por sentido) serão substituídas por dez novas faixas distribuídas na nova Avenida Binário do Porto (atualmente em construção) e a remodelação da Avenida Rodrigues Alves, que será convertida em Via Expressa (CDRUP, 2013). Além do espaço para a circulação de veículos rodoviários também estão previstas linhas novas de Veículos Leves sobre Trilhos (VLTs) transcorrendo o percurso das novas avenidas.

Desta maneira, a proposta de requalificação da Avenida Perimetral aqui apresentada não busca desqualificar a intenção atual do projeto em execução, mas sim demonstrar que é possível a utilização desta estrutura elevada ainda em sua intenção original (como corredor para circulação de transportes). Não exclui-se a possibilidade de construção da avenida Binário do Porto, mas sugere-se a conversão da avenida Rodrigues Alves em uma via para circulação exclusiva de ônibus (em corredores tipo Bus Rapid Transit - BRT) e VLTs, com praças e espaços públicos integrados para a população, além de uma via metroviária suspensa (na atual via elevada) em toda a extensão da atual Perimetral e trecho adicional. Para efeitos de diferenciação na nomenclatura, o novo corredor multimodal proposto será denominado Nova Perimetral.

\section{NOVA PERIMETRAL: PROJETO DO CORREDOR MULTIMODAL INTEGRADO}

De acordo com Ferraz (2004) e Bannister (2010) as políticas que buscam a integração e convergência de diversos sistemas de transportes podem formar ou contribuir para o funcionamento de uma rede mais dinâmica e fluída. Em concordância, Chiavenato (2005) e Barat (2007) mencionam que a integração é capaz de gerar economias de custos na operação e manutenção, bem como proporcionam maior eficiência na operação total do sistema de transportes.

Conforme mencionado, o corredor metroviário da Nova Perimetral coincide com parte do traçado planejado da linha 05 do Metrô Rio (CENTRAL, 2013) e consta no Plano Diretor de Transportes Urbanos 2012 (PDTU/RJ). Desta forma, justifica-se assim esta 
proposição a partir de estudos prévios e a utilização de estruturas já existentes para sua implantação.

$\mathrm{Na}$ proposta da Nova Perimetral são previstas 06 estações: Avenida Brasil (intersecção das avenidas Brasil e Presidente João Goulart), Novo Rio (em frente ao terminal rodoviário já existente), Cidade do Samba/Porto Novo (nas proximidades da atual Cidade do Samba), Praça Mauá, Praça XV e Santos Dumont. A exceção do trecho em elevado, todo o restante será construído em nível do solo. Todo este trecho conforta uma extensão de 09 quilômetros de percurso.

Complementar a este traçado indica-se a construção de quatro terminais metropolitanos integrados nas estações Avenida Brasil, Praça Mauá e Praça XV, além da adaptação e ampliação do atual Terminal Henrique Lotte (estação Novo Rio) para um terminal do porte proposto. No custo das estações Cidade Nova/Porto e Santos Dumont estão previstos pequenos terminal de ônibus, com pontos de parada para as linhas da via, pontos terminais e espaços para passagem de veículos VLT e paradas do corredor BRT que pode ser construído em nível do solo, logo abaixo da nova via elevada metroviária. Os terminais metropolitanos das estações Praça Mauá e Praça XV podem ser construídos nas áreas já existentes reservadas a paradas de ônibus municipais e metropolitanos, onde hoje encontram-se aglomerados de pontos de ônibus, tal como o terminal da estação Novo Rio pode ser reconstruído e ampliado onde já se encontra atualmente.

Ressalta-se também a integração multimodal ao longo de todo o corredor: com o sistema previsto de VLTs entre as estações Novo Rio e Santos Dumont, corredor BRT na parte inferior a via elevada (mesma extensão e traçado), o já existente Terminal Novo Rio e a estação das Barcas na Praça XV e o próprio Aeroporto Santos Dumont. Estes pontoschave de transporte expressam claramente o viés (ou objetivo) integrador multimodal pretendida, considerando-se apenas as estruturas já existentes ou em construção.

Em suma, este corredor metroviário pretende unificar em um mesmo espaço de circulação estações de embarque local, metropolitano, nacional e internacional, em modos terrestre, aéreo e aquático. Este é o principal benefício e vantagem competitiva deste corredor, principal mote de ineditismo para implantação no Brasil.

Desta forma, justifica-se assim esta proposição a partir de estudos prévios e a utilização de estruturas já existentes para sua implantação, reduzindo drasticamente seus custos de construção e implantação. Segundo a Agência Nacional de Transportes Terrestres (ANTT) o estudo para construção do primeiro Trem de Alta Velocidade (TAV), mais de $75 \%$ dos custos da construção de infraestruturas de transportes provém de obras civis e compensações/questões ambientais (ANTT, 2013). Ao considerar que a estrutura já está implantada e os impactos/compensações ambientais serão bem pequenos, admite-se que este corredor apresenta-se como solução sustentável.

Paralela e complementarmente a requalificação aplica-se 0 conceito de Desenvolvimento Orientado para Transporte Público (Transit Oriented Development TOD) conforme estudado por Bernick e Cervero (1996) e detalhado por TRCP (2005). Este 
indica a estruturação e adensamento das construções segundo a proximidade e oferta de transporte público. Assim, os novos empreendimentos empresariais previstos já estariam próximos a oferta de transporte necessária.

Além da qualificação técnico-paramétrica, TRCP (2005) indica alguns casos específicos de aplicação TOD em vias elevadas. Um exemplo concreto está no sistema de metrô elevado de Chicago no estado de Illinois (Estados Unidos da América), Chicago Elevated, onde diversas estações do sistema transpassam altos edifícios comerciais importantes localizados no CDB da Área Metropolitana de Chicago (Chicago Metropolitan Area ou Greater Chicago). Em algumas destas, ocorre a integração para ônibus locais e metropolitanos, trens terminais rodoviários suburbanos, nacionais e internacionais, bem como serviço de balsas (ferry boats) através do Lago Michigan.

Acevedo (2006), Serrano (2005) e Valentín (2007), demonstram como diretrizes TOD podem ser aplicadas a cidade de San Juan, capital portorriquenha (Caribe), ao analisar os bairros de Hato Rey, Santurce e Río Piedras, todos localidades destacadas dentro da Área Metropolitana de San Juan, por motivos econômico-financeiros e também no contexto de Transportes. Acevedo (2006) menciona que os corredores BRT Metro Urbano funcionam como alimentadores de municípios menores até o tronco principal, expresso pelo Trén Urbano, como é conhecido o sistema de metrô local. Ao passo que Serrano (2005) e Valentín (2007) indicam a estruturação de vias arteriais em zonas comerciais como principais eixos de circulação para transportes públicos, com vias segredadas e preferência de passagem, estas integradas ao sistema metroviário existente. Desta maneira, não apenas a circulação de grandes quantidades de passageiros é garantida de maneira mais rápida, mas principalmente, o seu direcionamento está imediatamente nas proximidades de pontos de interesse e circulação.

\section{NOVA PERIMETRAL: ASPECTOS TÉCNICO-FINANCEIROS}

De acordo com o Departamento Nacional de Infraestrutura de Transportes (DNIT, 2013), os viadutos têm como objetivo permitir uma melhor situação de escoamento de veículos. Por outro lado, com o acréscimo destes de maneira desordenada, estas soluções tornam-se inadequadas ao longo do tempo. Com o crescimento das cidades novas soluções devem ser apresentadas para garantir a manutenção da qualidade de vida. Toda estrutura elevada de transporte (pontes ou viadutos), devem atender a integridade das pessoas e dos veículos que por ela circulam. A sua rigidez é importante para que sua construção traga conforto, segurança e resista à vibração durante a passagem de cargas dinâmicas..

Segundo Neto (2006), para execução de um viaduto necessita de estudos prévios sobre Estruturas, Concreto Armado e Protendido, Mecânica dos Solos, Geologia, Hidráulica e Hidrologia, Matérias, Topografia, Estradas, Fundações, entre outros. Estes 
serviços citados demonstram a complexidade para elaboração de uma obra de infraestrutura desse porte. Existem duas classes de viadutos, sendo estes:

* Viadutos Rodoviários, onde as cargas acidentais são orientadas pela norma NBR 7188;

* Viadutos Ferroviários, onde as cargas acidentais são orientadas pela norma NBR 7189.

O mesmo autor afirma que as cargas atuantes sobre um viaduto estão separadas em duas partes: permanentes (peso próprio da estrutura, empuxo de terra, deformação imposta pela retração, fluência e recalque dos apoios) e acidentais (força centrífuga, choque lateral, efeitos de frenagem e aceleração, variações de temperatura, ação dos ventos e cargas dinâmicas).

A carga dinâmica foi pautada pela NBR 7188 - Trem Tipo Classe 45 (veiculo tipo de $450 \mathrm{KN}$ de peso total) pois, quando dimensionada, previa um trafego superior a 1000 veículos/dia. Este dimensionamento inicial do viaduto torna confortável a escolha em questão. Segundo a NBR 7189 diz que trens tipo TB 170 (veiculo tipo de $170 \mathrm{KN}$ de peso total) utilizado para transporte de passageiros em regiões metropolitanas ou suburbanas. Reduzindo sua carga dinâmica em até 165\%, pode-se usar este excedente de carga/peso para construção de terminais de passageiros.

Para a requalificação elaborou-se uma planilha de custo, considerando a implantação da malha ferroviárias (18 quilômetros, em duas vias de 09 quilômetros de extensão), 06 estações de passageiros tratamento urbanístico em combate da degradação da região e os outros elementos já mencionados na sessão anterior. O custo financeiro da Nova Perimetral foi obtido a partir de informações retiradas do relatório de custos unitários de construção da Agência Nacional de Transportes Terrestres (ANTT, 2013) e composição de preços unitários SICRO e levantamento de quantitativos sobre a estrutura elevada da Avenida Perimetral fornecidas por CDURP (2013).

Para este calculo foram consideradas as seguintes condições: lastramento de brita $(\mathrm{H}=0,30)$, dormentes protendidos (bitola $1,450 \mathrm{~mm}$ ) e trilhos (UIC 60), como mostra um estudo de custos unitários, para construção do Trem de Alta velocidade, ligando Rio de Janeiro - São Paulo - Campinas, apresentado por ANTT (com valores de serviços retirados de SICRO/SP). O valor do reajuste acrescido encontra-se de acordo com o Índice Nacional da Construção Civil (INCC) e o custo de eletrificação da via dado por CPTM (2012).

As estações de passageiros são projetadas como construções de até $2.500 \mathrm{~m}^{2}$, considerando-se $800 \mathrm{~m}^{2}$ pertencentes a estação propriamente dita e $1700 \mathrm{~m}^{2}$ materializados em um terminal metropolitano integrado. Apenas duas estações terão tamanho padrão (com simples paradas para ônibus, estações condensadas de BRTs e VLTs) enquanto as outras possuirão o tamanho máximo. O preço para a construção é de $\mathrm{R} \$ 1.024,63 / \mathrm{m}^{2}$, conforme o Sindicato da Indústria da Construção Civil de São Paulo 
(SINDUSCON-SP, 2013), majorando em até 40\% para detalhes de sofisticação do acabamento.

Serviços complementares como drenagem, execução da estrutura, não são considerados, pois a proposta está na utilização da via elevada em sua forma atual. Complementarmente, estes serviços já se encontram em execução pela operação urbana consorciada Porto Maravilha.

\section{CONCLUSÃO E RESULTADOS ESPERADOS}

Bruegamnn (2005) e Corrêa (2007) afirmam que as grandes cidades possuem características a expansão horizontal e vertical como características intrínsecas. Com o passar do tempo conurbam-se as suas vizinhas e formam aglomerados urbanos e metropolitanos. Bannister (2010) complementa esta informação ao mencionar que o dinamismo próprio de aglomerados urbanos e metrópoles demandam soluções inteligentes e dinâmicas, capazes de responder a demanda presente e futura de deslocamento de passageiros pelo espaço. Ainda, Corrêa (2006) corrobora a esta linha de pensamento ao apresentar estas zonas como redes urbanas integradas e interdependentes em suas atividades econômicas e demandas sociais.

Rossi (2003) apresenta o urbanismo sustentável como uma solução passível de aplicação para o crescimento e ordenamento urbano em vista a manutenção e implemento da qualidade de vida dos habitantes envolvidos. Silva (2012) complementa estas informações, em conjunto a Ferraz (2004) e Bannister (2010) ao afirmar que a escolha racional de um ou mais modos para uma determinada região é capaz de proporcionar deslocamentos mais rápidos e eficientes. Desta forma, todos os autores corroboram com a ideia de que a formação de uma rede integrada de transportes é um dos instrumentos capazes de proporcionar mais tempo livre aos passageiros e um ambiente mais limpo e saudável.

Chiavenato (2005), afirma também que a eficiência e racionalização de processos e sistemas é capaz de materializar maiores benefícios e vantagens competitivas para usuários diretos e indiretos do sistema, bem como seus respectivos operadores e gestores.

Esta proposta buscou apresentar uma alternativa ao quadro atual de transportes metropolitanos na Região Metropolitana do Rio de Janeiro (ou Grande Rio) em face ao atual estagnamento e insuficiência percebidos nos transportes públicos. Em um mesmo eixo integram-se deslocamentos para áreas dentro do município, para localidades da metrópole e destinos mais longínquos no Brasil e exterior. A multimodalidade apresentada é a principal vantagem competitiva deste corredor, pois não apenas integra-se redes já existentes, mas interliga-as com outras que estão isoladas proporcionando novas alternativas de deslocamento. 
Utilizando-se do projeto já existente da linha 05 proposto por CENTRAL, este corredor já possui os pré-requisitos para interligar ainda a Cidade Universitária da Universidade Federal do Rio de Janeiro (UFRJ), o Aeroporto Internacional do Rio de Janeiro (AIRJ), com integração deste ao corredor BRT TransCarioca (para as zonas Norte e Oeste da cidade), atualmente em construção, e a área comercial da llha do Governador a partir do tramo norte. Também é passível de integração com a rede metroviária já existente, pois a (planejada) estação Santos Dumont encontraria-se a menos de um quilômetro da estação Cinelândia da linha 01 (um) do Metrô Rio e, consequentemente, integraria o atual CDB do Rio de Janeiro a nova área de expansão comercial da zona portuária rapidamente, bem como a linha proposta a rede atual.

Admite-se que esta proposta não é suficiente para a implantação deste corredor e diversos estudos complementares são necessários até a sua definitiva execução. Contudo, o propósito esperado deste artigo é debater a questão da requalificação de estruturas urbanas em face à racionalização e integração de redes e sistemas de transportes, implementação da qualidade de vida metropolitana e a proposição de alternativa de uso a equipamentos e zonas urbanas degradas em processo acentuado de saturação e degradação. Com isto, no caso desta via, sua destinação inicial de corredor expresso de transportes permanece bem como seu uso é ampliado e integrado a nova dinâmica urbano-espacial em consolidação atual.

\section{REFERÊNCIAS}

ACEVEDO, Paul. El Impacto Sócio-Economico de la Alternativa Integrada de Transportes (ATI) en el Centro Urbano de Río Piedras. San Juan (Puerto Rico), Editora de la Universidad de Puerto Rico (UPR), 2007.

Agência Nacional de Transportes Terrestres (ANTT): www.antt.gov.br. Acesso em 10/04/2013.

BANISTER, David. Integrated Transport: From Policy to Practice. Londres e Nova York: Routledge, 2010.

BARAT, Josef. Logística, Transporte e Desenvolvimento Econômico. São Paulo: Editora CLA, 2007.

BERNICK, Michael e CERVERO, Robert. Transit Village in the 21st Century. Berkley: Editora McGraw Hill, 1996.

BRUEGMANN, Robert. Sprawl: A Compact History. Chicago: University of Chicago Press, 2005. 
BULLARD, Robert. Growing Smarter: Achieving Liviable Comunities, Environmental Justice and Regional Equity. Boston: The MIT Press, 2007.

CHIAVENATO, Idalberto. Administração Financeira: Uma Abordagem Introdutória. Rio de Janeiro: Elsevier, 2005.

Companhia de Desenvolvimento Urbano da Região do Porto do Rio de Janeiro (CDURP): www.cdurp.rio.ri.gov.br. Acesso em: 10/04/2013.

Companhia Estadual de Transporte e Logística (CENTRAL): www.central.ri.gov.br. Acesso em 10/04/2013.

Companhia Paulista de Trens Metropolitanos (CPTM): www.cptm.sp.gov.br. Acesso em 10/04/2013.

Departamento Nacional de Infraestrutura de Transportes (DNIT): www.dnit.gov.br. Acesso em 10/04/2013.

CORRÊA, Roberto Lobato. Estudos sobre a Rede Urbana. Rio de Janeiro: Bertrand Brasil, 2006.

CORRÊA, Roberto Lobato. Região e Organização Espacial. São Paulo: Ática, 2007.

FERRAZ, Antônio Clóvis. Transporte Público Urbano. São Carlos: Rima, 2004.

Instituto Brasileiro de Geografia e Estatística (IBGE): www.ibge.gov.br. Acesso em 10/04/2013.

NETO, Aiello Giuseppe Antônio. Apostila e Notas do Curso de Pontes. São Paulo: Material Didático de Aulas para o Curso de Engenharia Civil, 2006.

Opportrans Concessão Metroviária (MetrôRio): www.metrorio.com.br. Acesso em 10/04/2013

Operação Urbana Consorciada (UOC) Porto Maravilha: www.portomaravilha.com.br. Acesso em 10/04/2013.

ROSSI, Angela Maria Gabriella. (Organizadora). Ambiente Construído: Reflexões sobre o Desenvolvimento Urbano Sustentável. Rio de Janeiro: Sete Letras, 2003.

SERRANO, Carlos Alberto. Evaluación de La Movilidad em Santurce: Avenida de Diego como Eje de Integración. Mayagüez (Puerto Rico): Editora de la Universidad de Puerto Rico (UPR), 2005.

SILVA, Micaele. Renovação do STPU de Santa Maria/RS: Uma Nova Perspectiva para a Mobilidade Urbana. Santa Maria: Editora UFSM, 2012. 
TRCP. Research Results Diagnose 294. Washington D.C: The TRB Press, 2005.

VALENTÍN, Javier. La Estación de Trén como Herramienta para Crear el Espacio Público. Mayagüez (Puerto Rico), Editora de la Universidad de Puerto Rico (UPR), 2006. 